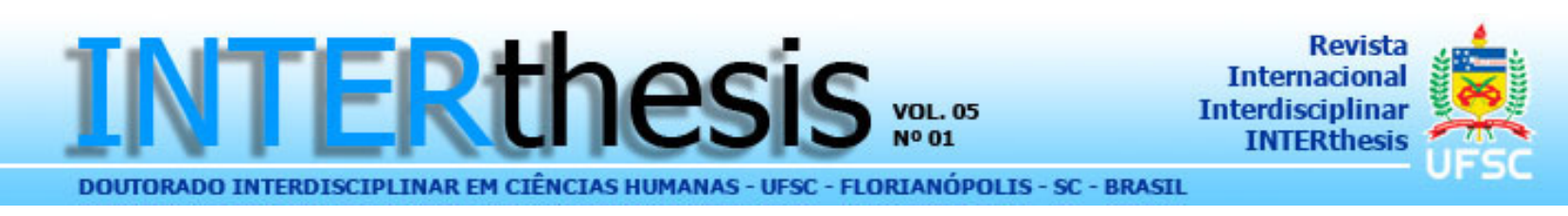

\title{
SOLIDARIEDADE E INTERVENÇÃO HUMANITÁRIA: A ATUAÇÃO BRASILEIRA NO HAITI COMO NOVO PARADIGMA JURÍDICO DE SOLIDARISMO INTERNACIONAL
}

\section{SOLIDARITY AND HUMANITARIAN INTERVENTION: A BRAZILIAN ACTION IN HAITI AS A NEW LEGAL PARADIGM OF INTERNATIONAL SOLIDARISM}

\section{LA SOLIDARIDAD Y LA INTERVENCIÓN HUMANITARIA: LA ACCIÓN BRASILEÑA EN HAITÍ COMO NUEVO PARADIGMA JURÍDICO DEL SOLIDARISMO INTERNACIONAL}

\section{RESUMO}

\section{Geovane Machado Alves ${ }^{1}$}

Hodiernamente, em virtude do crescimento exponencial do saber humano, oriundo inegavelmente da proliferação das disciplinas acadêmicas, cada vez mais torna-se impossível qualquer análise mais profunda da sociedade, encarando-a apenas sob um olhar solipsista e distanciado dos demais ramos e dimensões do conhecimento. Neste sentido, a presente pesquisa se propõe a formular novos conceitos e perspectivas, capazes, por sua vez, de fomentar a elaboração de novas matizes teóricas e modelos de observação da realidade, tendo como pressuposto essencial o exame dos elementos necessários à construção de um novo paradigma jurídico de intervenção humanitária. Para tanto, verificar-se-á, inicialmente, os elementos que fazem parte do conceito de solidariedade, a fim de, posteriormente, propor sua aplicação ao Direito Internacional Humanitário, considerando, neste ponto, as especificidades envolvendo a atuação brasileira no Haiti. Desta maneira, a presente abordagem da questão relativa à ajuda humanitária internacional, visa alvitrar à inauguração de uma nova espécie de solidariedade internacional, na qual se passa a conceber a intervenção humanitária internacional não mais como um simples envio de tropas ou mantimentos, mas sim como o momento indispensável para a formulação de políticas públicas transnacionais.

Palavras-chave: Solidariedade; Intervenção humanitária; Solidarismo; Políticas públicas; Haiti

\section{ABSTRACT}

Currently, considering the exponential growth of the human knowledge, undeniably due to the proliferation of academic disciplines, any deeper analysis of society becomes more and more impossible, viewing it only from an individualist look and distant from the other branches and dimensions of knowledge. Therefore, the present study aims to formulate new concepts and perspectives, able, in turn, to foster the development of new theoretical nuances and models of observation of reality, and having, as an essential assumption, the

\footnotetext{
${ }^{1}$ Mestrando em Direito Público pela Universidade do Vale do Rio dos Sinos - UNISINOS, São Leopoldo/RS. Graduado em Direito pela Pontifícia Universidade Católica de Minas Gerais - PUC-MG. E-mail:

gebh@bol.com.br
}

R. Inter. Interdisc. INTERthesis, Florianópolis, v.5, p. 47-65, jan./jul. 2008. 
examination of the elements necessary for the construction of a new legal paradigm of humanitarian intervention. At first, we will analyze the elements that are part of the concept of solidarity so that, afterwards, we can propose their application to the humanitarian international law, considering, at this point, the specificities surrounding the Brazilian action in Haiti. Thus, this approach on the issue of international humanitarian aid aims at proposing the inauguration of a new kind of international solidarity, which will conceive the international humanitarian intervention not as a mere sending of troops or supplies, but as the necessary moment for the formulation of transnational public policies.

Key-words: Solidarity; Humanitarian intervention; Solidarism; Public policy; Haiti

\section{RESUMEN}

Actualmente, teniendo en cuenta el crecimiento exponencial del conocimiento humano, venga innegable la proliferación de disciplinas académicas, cada vez más se convierte en imposible cualquier análisis más profundo de la sociedad, al considerar que sólo en una lejana mirada individualista y los otros sectores y dimensiones del conocimiento. Por lo tanto, el presente estudio tiene por objeto formular nuevos conceptos y perspectivas, capaces, a su vez, a fomentar el desarrollo de nuevos matices teóricos y modelos de observación de la realidad, y como elemento esencial el examen de los elementos necesarios para la construcción de un nuevo paradigma jurídico de la intervención humanitaria. Así, se examinarán, en un principio, los elementos que forman parte del concepto de solidaridad para luego proponer su aplicación al derecho internacional humanitario, teniendo en cuenta este punto, los detalles que rodean a la acción de Brasil en Haití. Por lo tanto, este enfoque sobre la cuestión de la ayuda humanitaria internacional, tiene como objetivo proponer a la inauguración de un nuevo tipo de solidaridad internacional, que el diseño de la intervención humanitaria internacional no como un mero envío de tropas o suministros, pero como el momento necesario para la formulación de las políticas públicas transnacionales.

Palabras-clave: Solidaridad; La Intervención humanitaria; Solidarismo; Políticas públicas; Haití

\section{INTRODUÇÃO}

Hodiernamente, em virtude do crescimento exponencial do saber humano, oriundo inegavelmente da proliferação das disciplinas acadêmicas, cada vez mais torna-se impossível qualquer análise mais profunda da sociedade, tendo por base apenas um olhar solipsista e distanciado dos demais ramos e dimensões do conhecimento.

Na realidade, "somente uma inteligência que se dá conta da dimensão dos conflitos atuais poderá fazer frente à complexidade de nosso mundo e ao desafio contemporâneo de autodestruição material e espiritual de nossa espécie." (CARTA DA TRANSDICIPLINARIDADE, 1994, p. 193).

Neste diapasão, exsurge o conceito de transdicisplinaridade como uma maneira de não mais reduzir o ser humano a uma mera definição fundada em estruturas formais, mas 
sim de proporcionar uma análise mais complexa do ser, partindo-se de uma confrontação das disciplinas acadêmicas no ponto de abertura que as atravessa e as ultrapassa (CARTA DA TRANSDICIPLINARIDADE, 1994). Tal abertura permite a formulação de novos conceitos e perspectivas - até então enterradas num formalismo, muitas vezes, estéril - que serão capazes de fomentar a elaboração de novas matrizes teóricas e paradigmas de observação da realidade.

Por seu turno, as Ciências Jurídicas também se apropriarão deste significativo universo conceitual para construir novos paradigmas teóricos de análise e compreensão da sociedade. Sendo assim, considerando o atual cenário internacional, marcado pela eclosão de inúmeros conflitos armados e crises diplomáticas, a presente pesquisa, concebida a partir de uma perspectiva transdisciplinar, visa traçar os elementos fundamentais para a construção de um novo paradigma jurídico de intervenção humanitária.

Desta forma, num primeiro momento, serão identificados os elementos essenciais que fazem parte do conceito de solidariedade, a fim de, posteriormente, propor sua aplicação ao Direito Internacional Humanitário. Para tanto, serão realizadas breves incursões sobre as especificidades envolvendo a atuação brasileira no Haiti, com o intuito de colher os princípios necessários à construção desse inovador paradigma de solidarismo internacional, marcado consideravelmente por uma crescente transnacionalização de políticas públicas.

\section{A FORMULAÇÃO DO CONCEITO DE SOLIDARIEDADE}

Locução cada vez mais freqüente nos atuais discursos políticos e ideológicos, a "solidariedade" tem se tornado tema constante nos círculos de debates, encontros sociais, e, até mesmo, vem sendo empregada como plataforma institucional para o lançamento de inúmeros programas populares do governo. Para tanto, basta citar exemplos como: Alfabetização Solidária, Comunidade Solidária, Universidade Solidária, dentre outros (ALMEIDA, 2007).

Entrementes, é bastante provável que o termo solidariedade esteja sofrendo mudanças, readequações, reformulações, negações ou mesmo que esteja sendo tomado como inadequado para dar conta de tantas explicações sociológicas de nossa época

R. Inter. Interdisc. INTERthesis, Florianópolis, v.5, p. 47-65, jan./jul. 2008. 
(LOLIS, 2007).

\begin{abstract}
Para o senso comum a solidariedade está fortemente ligada ao campo das emoções. Seria uma sensibilidade para com os menos favorecidos que leva a uma atitude de caridade. A fragilidade desta concepção está em sua unilateralidade. Os ricos deveriam ser solidários com os pobres. Mas é possível solidariedade sem reciprocidade? Parece nos que o equívoco está em colocar o significado da solidariedade imediatamente no campo do agir, da ética, dos resultados. Sabemos que $\mathrm{o}$ agir segue o ser. Portanto, somente podemos tomar atitudes solidárias porque existe uma solidariedade essencial em nossa identidade humana (ALMEIDA, 2007).
\end{abstract}

Destarte, para se compreender de maneira correta o conceito de solidariedade, mister se faz situá-la no seu contexto ideológico, considerando-a a partir de uma concepção nitidamente transdisciplinar (FARIAS, 1998).

Como é sabido, no ideário ocidental, o conceito de solidariedade não é recente. Para alguns, sua origem estaria atrelada a duas vertentes intelectuais: o estoicismo e o cristianismo primitivo (DUVIGNAUD, 1995). Os juristas romanos também utilizaram da palavra solidariedade para designar o laço que une entre si os devedores de uma quantia, de uma obrigação, em relação à qual cada um é responsável pelo todo.

Todavia, antes de falar numa concepção jurídico-ideológica, é preciso destacar que a solidariedade, em sua concepção mais primitiva, está intimamente atrelada à idéia de uma espécie de laço sangüíneo, ou não, que une os homens entre si segundo formas que se apresentam tradicionalmente ou de maneira natural, devido ao seu prolongamento na história das sociedades (DUVIGNAUD, 1995).

Neste diapasão, destaca-se a família como a forma mais simples de que devemos partir para compreender a evolução das sociedades e da concepção de solidariedade. Para Duvignaud (1995, p. 25), a família é "uma forma de sociabilidade tão universal que alguns a chamam natural: um útero social para abrigar a cria humana, da qual se disse que uma espécie de nascimento prematuro lhe impunha uma longa proteção".

Na realidade, trata-se a família de uma forma social involuntária e necessária que liga os homens entre si, de uma maneira diferente e infalível. Todavia, as famílias, que antigamente poderiam ser designadas de clãs ou hordas, não estavam isoladas de outras que viviam em condições semelhantes. Tratam-se de estruturas moleculares que passaram a formar em conjunto a sociedade. Numa família todos os membros mantém 
relações entre si que podem ser classificadas como domésticas. As afinidades que a comunidade de sangue engendra são principalmente aquelas que os mantêm unidos (RODRIGUES, J. A., 2005).

Desta forma, a estrutura das cidades não são apenas uma acumulação quantitativa de pessoas, mas sim habitantes que estabelecem entre si relações, que vão além de uma mera vizinhança ou dependência, trata-se de uma cooperação mútua com contínua especialização de tarefas. Durante este convívio face a face entre seres vivos reunidos no interior de uma coletividade, munidos da tarefa de uma cooperação mútua, surgem solidariedades efêmeras, resultado de uma formação cultural que decorre da vida urbana (DUVIGNAUD, 1995).

O espaço onde se dará as manifestações mais simples às consideravelmente complexas de solidariedade, se é que se pode fazer tal distinção, será o espaço social formado pelas relações existentes desde sua estrutura mais insipiente, qual seja a família, até as cidades e os Estados. Nessa perspectiva, diz-se que a solidariedade é uma prática alimentada pela sua própria complexidade social.

$\mathrm{Na}$ modernidade, ocorrerá um salto importante no pensamento filosófico e sociológico que suscitará elementos essenciais para a formação do conceito de solidariedade. Neste diapasão, expressões como caridade e filantropia passam a adquirir notória importância no contexto das relações sociais. "O dever de prestar ajuda àqueles que passam necessidade são preocupações da Revolução Francesa que, depois de algumas hesitações no início e antes da reação termidoriana, colocava o direito ao socorro público" (FARIAS, 1998, p. 188). Neste sentido, a Constituição Francesa de 1793 passa a estabelecer o que alguns autores chamariam posteriormente, de um direito fundado na justiça social.

Desta forma, a noção de "dever de assistência" forma-se progressivamente no curso do século XIX. Segundo, Duvignaud (1995, p.122):

Contudo, não tinha já Fichte, anteriormente, procurado, desde 1795, libertar o pensamento da 'coisa em si' kantiana, tal como a Revolução de 1789 tinha libertado os franceses das instituições arcaicas? A liberdade política não é o resultado do aparecimento em cena da razão, mas o efeito de uma humanidade em marcha procurando novas vias: "Todos os indivíduos estão integrados na grande unidade do espírito".

R. Inter. Interdisc. INTERthesis, Florianópolis, v.5, p. 47-65, jan./jul. 2008. 
Assim, surge a idéia de que as divisões profissionais engajavam fisicamente e moralmente o indivíduo frente à coletividade humana, defendida por Augusto Comte. Para ele, será através das noções de dever social, de dívida social, que se poderá ter a exata noção da rede de relações sociais e da solidariedade concreta que perpassa a sociedade. Segundo Comte, é no equilíbrio de deveres que se constitui o espaço de liberdade coletiva (FARIAS, 1998).

Entretanto, não se pode falar em solidariedade sem mencionar as valiosas contribuições de Proudhon. Para ele, a sociedade é um ser vivo, dotado de inteligência e de atividade próprias, regido por leis especiais que só a observação pode descobrir e cuja existência se manifesta não sob a forma física mas pelo concerto e pela íntima solidariedade de todos os seus membros (DUVIGNAUD, 1995). Proudhon preconizava uma filosofia ligada ao cotidiano da vida, onde o mundo social é concebido no campo das ações múltiplas dos grupos (FARIAS, 1998).

Contudo, é somente no fim do século XIX que advém a lógica da solidariedade como um discurso congruente que não mais se confunde com expressões como "caridade" ou "filantropia". A lógica da solidariedade passa a trazer consigo uma nova forma de pensar a sociedade, não somente um sistema de proteção social, mas também como um fio condutor indispensável à construção e à conceitualização das políticas sociais (FARIAS, 1998), cuja contribuição mais marcante, depois das primeiras tentativas de síntese feitas por Charles Renouvier, Charles Secrétan, Alfred Fouillé, Marion e Charles Gide, se dá com a sistematização do discurso da solidariedade elaborada conceitualmente por Léon Bourgeois e Durkheim.

Para Durkheim, pode-se chamar de consciência coletiva ou comum, o conjunto de crenças e de sentimento comuns à média dos membros de uma mesma sociedade, formando um sistema determinado que tem sua vida própria (RODRIGUES. J. A., 2005). Com efeito, a consciência coletiva independe das condições particulares em que se encontram os indivíduos; estes passam e ela permanece (RODRIGUES. J. A., 2005).

Trata-se portanto de algo inteiramente diverso da própria consciência individual. $\mathrm{Na}$ realidade, ela forma o tipo psíquico da sociedade. Nessas condições, entende Durkheim que não somente todos os membros do grupo são individualmente atraídos uns pelos outros porque se assemelham, mas são ligados também pela condição de existência deste tipo coletivo, ou seja, a sociedade que eles formam mediante sua reunião 
(RODRIGUES. J. A., 2005).

Durkheim, ainda, vai dizer:

Os cidadãos não apenas se querem e se procuram entre si de preferência aos estrangeiros, mas também amam sua pátria. Eles querem-na como a si mesmos, esforçam-se para que ela sobreviva e prospere, porque, sem ela haveria toda uma parte de sua vida psíquica cujo funcionamento seria entravado. Inversamente, a sociedade diligencia para que eles apresentem todas essas semelhanças fundamentais, porque isto é uma condição de coesão (RODRIGUES. J. A., 2005, p. 75).

Verifica-se, portanto, que, para Durkheim, existe uma solidariedade social decorrente de um certo número de estados de consciência comuns a todos os membros de uma mesma sociedade (RODRIGUES. J. A., 2005). A parcela que a solidariedade social tem na integração geral da sociedade depende evidentemente da extensão mais ou menos significativa da vida social abrangida e que regulamenta a consciência comum.

Por conseguinte, no ideário da comunidade se expressa a síntese integrativa das pessoas que a formam, cada uma delas disposta a superar o seu egoísmo, sem evidentemente abrir mão da respectiva individualidade. Em cada tomada de posição diante dos inumeráveis problemas sociais, a comunidade busca a unidade, assumindo as responsabilidades sociais que serão intensificadas na medida em que a consciência coletiva for assumindo contornos bem definidos (BALERA, 2007).

Para Durkheim a solidariedade provém da consciência coletiva que, predominando sobre a consciência individual, aponta para a necessidade de compreensão da solidariedade como aspecto diferenciado da dicotomia público $\mathrm{x}$ privado, preordenando o que pode vir a se constituir na responsabilidade social. Entrementes, o liberalismo optou por outros caminhos. E, mesmo as doutrinas mais modernas ainda seguem afirmando que a solidariedade consiste em assunto do domínio privado (BALERA, 2007).

$\mathrm{Na}$ contramão das doutrinas liberais, os solidaristas procuram oferecer uma visão comum do mundo para demonstrar que os homens, quer queiram ou quer não, são devedores e credores uns em relação aos outros, não significando, por sua vez, que a existência dessas relações recíprocas não traga defeitos em seu bojo (RODRIGUES, J. A., 2005). Como é sabido, a sociedade não produz somente efeitos conforme os princípios de igualdade e de justiça, razão pela qual o discurso solidarista se apresenta também como um projeto ético e moral, querendo trabalhar por uma reforma direcionada

R. Inter. Interdisc. INTERthesis, Florianópolis, v.5, p. 47-65, jan./jul. 2008. 
para uma maior solidariedade dos indivíduos.

Todavia, no fim do século XIX e início do século XX, a tese da solidariedade, ao angariar espaço nos círculos de discussões político sociais, começa a exercer uma forte influência sobre alguns juristas, o que contribuiu notoriamente para a discussão sobre a inserção desta temática em assuntos que, até então, estavam restritos à questões meramente comerciais e bélicas.

Na realidade, para os juristas engajados no solidarismo, o direito, a solidariedade e a democracia caminham juntos. O discurso do solidarismo jurídico não é somente uma maneira de se dizer o direito ou se falar sobre ele, trata-se de um novo olhar sobre a sociedade como um todo, abrangendo também sua esfera política (FARIAS, 1998). Contudo a articulação das esferas jurídica e política se dará de maneira muito particular.

O discurso do solidarismo jurídico pretende ser o fundamento do Estado Democrático de Direito, ou seja, ele considera o campo político no Estado democrático indispensável, a única possível, para a realização do direito no seio de uma organização social. Trata-se de se almejar um Estado, onde se considera a soberania de um direito de solidariedade engendrado pela comunidade política subjacente à organização sobreposta (FARIAS, 1998).

Esta maneira de se pensar o solidarismo jurídico, contribuiu para a elaboração de uma nova forma de solidariedade, aquela cujos fundamentos e campos de atuação se darão no âmbito do relacionamento entre Estados soberanos, no nítido intuito de fomentar o fortalecimento de bases nacionais sólidas capazes de gerar um crescimento contínuo e equilibrado de nações menos favorecidas.

Trata-se, na verdade, de uma construção de novos paradigmas de diplomacia, uma vez que o mundo foi impelido, até agora, por uma dialética em que a dominação e a submissão - alimentadas por egoísmos e ressentimentos - prevaleceram sobre fatores positivos e dinâmicos de progresso.

Neste diapasão, ensina Albert Tévoédjré (1981, p. 141):

Com certeza, não é neles, infelizmente, que se pensa, quando se diz "Nós, povos das Nações Unidas". Mas esta maioria esquecida, estes abandonados, estes marginalizados, estes desempregados, estes doentes reclamam o justo direito de viver. É urgente atender a esta legítima reivindicação, favorecendo a construção de uma nova ordem internacional. A ordem, que reina, hoje, é, aos olhos de muitos:

R. Inter. Interdisc. INTERthesis, Florianópolis, v.5, p. 47-65, jan./jul. 2008. 


\begin{abstract}
- uma "ordem" sem diálogo, um universo cujos dirigentes se abandonam a um solilóquio, que acostumamos escutar passivamente há séculos;

- uma "ordem" baseada em privilégios, cujas estruturas permitem a uma minoria ditar leis e regras de comportamento à maioria;

- uma "ordem" em que, na maioria dos casos, os princípios de justiça, de eqüidade e de solidariedade cedem lugar ao desejo de poder e lucro.
\end{abstract}

Assim, o perigo reside, principalmente, no tipo de relações internacionais geradas pelo sistema dos impérios, hoje contestados, e que deu origem a instituições cuja unidade é imposta de fora (TÉVOÉDJRÉ, 1981). Os especialistas em associações, no direito alemão, opõem esta forma de instituição, chamada Herrschaft, baseada na dominação, a um outro tipo de relação social, Genossenschaft, no qual a unidade se forma democraticamente.

Neste ponto, quando se fala em relações internacionais baseadas, não apenas no intuito de auferir vantagens financeiras ou políticas, mas fulcradas no nítido interesse de se reconstruir nações arrasadas materialmente e socialmente, mister se faz analisar um pouco da atuação brasileira na Operação de Paz da Organização das Nações Unidas ONU para o Haiti, cujo modelo tem proporcionado a elaboração de uma nova forma de diplomacia, fundada na solidariedade, cuja manifestação mais sensível pode ser claramente observada através de uma crescente e expressiva transnacionalização de políticas públicas.

\title{
3 A ATUAÇÃO BRASILEIRA NO HAITI E A CONSTRUÇÃO DE UM NOVO PARADIGMA DE SOLIDARISMO INTERNACIONAL
}

O Brasil, ao contrário do ideário das grande potencias mundiais, que acreditam na obtenção de armas de destruição de massa, como meio mais eficaz de manutenção da hegemonia, sempre defendeu que o acúmulo de armas, ao invés de assegurar a paz, gera considerável insegurança, inviabilizando, indubitavelmente, a construção de uma ordem política e internacional justa (ALMINO, 2002).

Nesta perspectiva, o país, repetidas vezes, exerceu um papel importante na formação de organizações e sistemas de integração regionais e universais, para tanto cumpre citar a Organização dos Estados Americanos - OEA , o Mercado Comum do Sul -

R. Inter. Interdisc. INTERthesis, Florianópolis, v.5, p. 47-65, jan./jul. 2008. 
MERCOSUL e o seu sistema de prevenção formalizado pelo Protocolo de Ushuaia, bem como a Organização das Nações Unidas - ONU, sucessora da antiga Liga das Nações, que, por sua vez, possui um proeminente papel na busca da manutenção da paz entre os povos (SEITENFUS, 2007a).

Desta maneira, para se ter uma idéia da dimensão da participação da ONU na promoção de soluções pacíficas aos litígios, cumpre ressaltar que em fins de junho de 1993, mais de 77.000 oficiais, soldados e policiais de 75 países serviam nas 14 operações de paz das Nações Unidas então em atividade. Somavam-se a eles, em Nova York e nas missões mundo a fora, o pessoal civil contratado pela Organização ou cedido pelos Estados-membros para uma determinada operação, os transferidos provisoriamente de outra missão ou dos quadros regulares das Nações Unidas, e o pessoal de apoio contratado localmente ou fornecido por empresa internacional de prestação de serviços (CARDOSO, 1998).

Cumpre mencionar, ainda, que nas sedes da Organização em Nova York, Genebra e Viena, e de suas comissões regionais, as Nações Unidas empregam cerca de 14.000 profissionais e funcionários de serviços gerais (CARDOSO, 1998). Ademais, conforme Afonso José Sena Cardoso (1998, p. 11),

\begin{abstract}
Em termos de recursos financeiros, a comparação é igualmente expressiva. O orçamento regular das Nações Unidas tem sido da ordem de US\$ 1 bilhão anual. As atividades custeadas com contribuições voluntárias na Organização central, Programa das Nações Unidas para o Desenvolvimento - PNUD, Fundo de População - FNUAP, Fundo da Criança - UNICEF, Alto Comissariado das Nações Unidas para Refugiados - ACNUR e outros programas de assistência e emergência têm consumido, em média, US\$ 1,5 bilhão por ano. Já as despesas com as forças de paz e missões de observação das Nações Unidas são hoje projetadas em, pelo menos, US $\$ 2,8$ bilhões anuais.
\end{abstract}

Além disso, no que tange mais especificamente à participação da ONU nas Operações de Manutenção da Paz, vale citar brevemente as palavras do professor Ricardo Seitenfus (2007):

Segundo o Departamento de Operações de Manutenção da Paz da ONU (DPKO), 107 Estados participavam como contribuintes, no final de 2005, nas operações de paz das Nações Unidas. Mais de 70 mil homens em missão estavam envolvidos nestas operações. A grande maioria (94\%) do pessoal civil, militar e policial é oriunda dos países em desenvolvimento, sendo que o Brasil ocupava a $14^{\mathrm{a}}$ posição entre os Estados contribuintes às missões de paz.

R. Inter. Interdisc. INTERthesis, Florianópolis, v.5, p. 47-65, jan./jul. 2008. 
Assim, em face da atual conjuntura internacional, coube ao Brasil dar inicio a sua participação nas missões de paz organizadas pela ONU, em 1948, com o envio de dois militares para a Comissão Especial das Nações Unidas para os Bálcans - UNSCOB, que operou na Grécia de 1947 a 1951. Desde então, o país participou de vinte e seis missões de paz ou civis sob a égide da ONU e de missões estabelecidas pela Organização dos Estados Americanos - OEA, com observadores militares, policiais, peritos eleitorais, especialistas em saúde ou com tropas armadas, como em Suez, na República Dominicana, Moçambique, Angola, Timor Leste e, mais recentemente, no Haiti (AGUILLAR, 2002) que, em especial, propiciará os elementos necessários à inauguração desse novo paradigma jurídico de solidariedade internacional.

A participação brasileira no Haiti teve início no primeiro semestre de 2004 , quando o país aceitou participar, com o envio de 1200 militares, da missão de paz organizada pela ONU, denominada MINUSTAH. Criada pela Resolução $n^{\circ} 1542$, aprovada pelo Conselho de Segurança em sua $4961^{\text {a }}$ sessão, celebrada em 30 de abril de 2004, coube a MINUSTAH, dentre outras, as seguintes tarefas:

I. Entorno seguro y estable: (...) d) Prestar asistencia en el restablecimiento y mantenimiento del Estado de derecho, la seguridad pública y el orden público en Haití, prestando, entre otras cosas, apoyo operacional a la Policía Nacional de Haití y el Servicio de Guardacostas de Haití, así como en el fortalecimiento institucional, incluido el restablecimiento del sistema penitenciario; (...) II. Proceso político: a) Apoyar el proceso constitucional y político que se ha puesto en marcha en Haití, incluso ofreciendo buenos oficios, y fomentar los principios del gobierno democrático y el desarrollo institucional; (...) III. Derechos humanos: a) Apoyar al Gobierno de transición, así como a las instituciones y grupos haitianos de derechos humanos, en sus esfuerzos por promover y proteger los derechos humanos, particularmente los de las mujeres y los niños, a fin de asegurar la responsabilidad individual por los abusos de los derechos humanos y el resarcimiento de las víctimas (CONSELHO DE SEGURANÇA DA ONU, 2004).

$A b$ initio, a mencionada Resolução teve como objetivo primordial substituir a Resolução $n^{\circ}$ 1529/2004, do Conselho de Segurança, que havia se reunido às pressas em razão da vacância do poder no Haiti decorrente da partida, em 29 de fevereiro de 2004, do Presidente Jean-Bertrand Aristide.

Para que se possa ter a exata dimensão dos problemas enfrentados nos últimos anos pela população haitiana, mister ser faz conhecer um pouco da história daquele país. O Haiti freqüentemente é visto no Caribe como um país africano por excelência e, na 
América, o país negro, o país do vodu e da coumbite, do tambor e do créole, coberto de cayes (casas típicas) e animado por costumes ancestrais (GRONDIN, 1985). O Haiti é o único Estado independente constituído por africanos fora da África, uma república negra nas Américas (SEITENFUS, 2007b).

Entrementes, o Haiti deve ser considerado e analisado como um país cujas peculiaridades transcendem a esses poucos aspectos citados. Trata-se do país onde ocorreu a primeira revolução nas colônias do Sul e que estabeleceu a primeira república negra do mundo (GRONDIN, 1985). A emancipação haitiana compreendeu não somente a luta contra a metrópole, mas também a luta contra os senhores. A maioria dos negros que lutaram pela liberdade consistiam de escravos nascidos na África e recém-chegados ao Haiti.

Entretanto, apesar de ser a primeira colônia latina a romper os laços que mantinha com a Europa, o Haiti caracteriza-se pela crônica instabilidade política que assola o país. Golpes, contragolpes, revoluções, intentonas e guerras entre clãs permeiam a trajetória dessa república (SEITENFUS, 2007b). Como bem caracterizou Marcelo Grondin (1985, p. 11):

\footnotetext{
Além disso, as lutas internas pelo poder $\mathrm{e}$ as permanentes intervenções estrangeiras de todo tipo, desde a Colônia até o presente, particularmente a francesa, a inglesa, a espanhola e a norte-americana, não permitiram a formação de uma homogeneidade compacta da população. Nem africano nem americano, profundamente caribenho, o Haiti ainda é somente um país; não uma nação. Essa situação de transição e de divisão se reflete nos elementos culturais da população e condiciona suas potencialidades em relação ao desenvolvimento.
}

Caracterizado fundamentalmente por conturbados períodos políticos, o Haiti de 1986 a 1990 foi dirigido por uma série de governos provisórios. Em 1987, houve a elaboração de uma nova Constituição. Posteriormente, em dezembro de 1990, JeanBertrand Aristide foi eleito com $67 \%$ dos votos. Todavia, poucos meses depois, Aristide foi deposto por um golpe militar tendo sido restaurada novamente a ditadura no país.

Em 1994, Aristide retorna ao poder no Haiti, com auxílio do Estados Unidos. Entretanto, o ciclo de violência, corrupção e miséria, que a tanto tempo assolava o país, não é interrompido. Por conseguinte, em dezembro de 2003, sob pressão crescente da ala rebelde, Aristide promete novas eleições dentro de seis meses. Contudo, os protestos Anti-Aristide, em janeiro de 2004, fazem várias vítimas na capital Porto Príncipe. Então,

R. Inter. Interdisc. INTERthesis, Florianópolis, v.5, p. 47-65, jan./jul. 2008. 
no dia 29 de fevereiro de 2004, com o avanço dos rebeldes, Aristide renuncia e foge para a África. Por sua vez o Haiti sofre intervenção da ONU, através do envio de uma Força Interina Multinacional (HISTÓRIA DO HAITI, 2007).

Desta forma, o interesse precípuo da ONU em construir um ambiente seguro e estável no Haiti, além do respeito aos direitos humanos e a concretização do processo político tornou-se patente com a edição da mencionada Resolução n 1542, de 30 de abril de 2004. Conseqüentemente, não é difícil perceber que o problema enfrentado pelo Haiti atualmente não perfaz exclusivamente a área militar, embora muitos tratem desta maneira.

Aliás, como bem relatou o ex-Comandante da Força Militar da Missão das Nações Unidas para Estabilização do Haiti, General-de-Divisão Augusto Heleno Ribeiro Pereira (2005, p. 07), "o país padece mais de problemas sociais, ecológicos e políticos do que, propriamente, militares. O problema passa a ser militar na medida em que uma Força de Paz lhe é vital, mas não é um país onde a ação militar, por si só, possa resolver todos os conflitos".

De fato, diante desta problemática sobremodo complexa vivenciada pelo Haiti, coube ao Brasil atuar de maneira ativa e eficaz na reconstrução daquele país, e são exatamente através das características da atuação brasileira no Haiti que se buscará identificar esse novo paradigma jurídico solidarista de intervenção humanitária, cujos elementos essenciais deste inovador conceito perfazem a idéia de transnacionalização de políticas públicas.

Para que se possa compreender melhor este novo conceito, cumpre destacar algumas breves palavras pronunciadas pelo Ministro de Estado das Relações Exteriores do Brasil, Embaixador Celso Luiz Nunes Amorim, em discurso proferido na Reunião Especial do Conselho de Segurança das Nações Unidas sobre o Haiti, realizado em Nova York, no dia 12 de janeiro de 2005, verbis:

Nós - as Nações Unidas, os países da América Latina e do Caribe e os próprios haitianos - temos o dever de contribuir para a realização dessa esperança. $O$ futuro do Haiti tornou-se hoje um tema de interesse do conjunto da comunidade internacional; a MINUSTAH e as iniciativas de cooperação técnica e financeira constituem um teste da mais alta importância para que as Nações Unidas demonstrem a sua capacidade de atender a situações cuja solução se situa além da simples estabilização político-militar e envolve uma verdadeira reconstrução nacional. Muitas vezes repeti que o sucesso da Missão de Estabilização das

R. Inter. Interdisc. INTERthesis, Florianópolis, v.5, p. 47-65, jan./jul. 2008. 
Nações Unidas no Haiti se baseia em três pilares interdependentes e igualmente importantes: a manutenção da ordem e da segurança; o incentivo ao diálogo político com vistas à reconciliação nacional; e a promoção do desenvolvimento econômico e social. Não se trata de três "passos" diferentes, nem podem seguirse uns aos outros no tempo. $O$ atendimento simultâneo aos três pilares é condição indispensável para a reconstrução do Haiti. O que necessitamos é de um acordo entre todos, que una a comunidade internacional e as forças políticas haitianas em um compromisso de longo prazo. (...) Está claro que a normalização no Haiti não se dará sem a decidida participação da comunidade internacional na promoção do seu desenvolvimento econômico e social. Esta é a área em que menos fizemos e em que o Haiti mais necessita do nosso apoio. Por piores que sejam outras tragédias, as quais acompanhamos atentamente e que merecem uma resposta urgente e coordenada da comunidade internacional, não nos podemos permitir baixar o grau de prioridade que assumiu o Haiti na agenda internacional. Se considerarmos as taxas de mortalidade infantil, por exemplo, não é exagero dizer que o Haiti sofreu os efeitos de um verdadeiro tsunami econômico e social nos últimos dois séculos. O Haiti é uma prova contundente da necessidade de desenvolver mecanismos adequados para impedir a deterioração das situações nacionais e para assistir os países recém-saídos de situações de conflito ou mesmo para evitá-las.

Mais recentemente, em novo discurso do Ministro das Relações Exteriores, realizado na sessão de abertura da Reunião Internacional de Alto Nível sobre o Haiti Brasília, no dia 23 de maio de 2006, o Embaixador Celso Amorim novamente afirmou que, in verbis:

Ao responder ao chamado da ONU, o Brasil entendeu que a situação do Haiti não se resumia a um problema de restauração da segurança pública. Na origem da crise de segurança existia, a nosso ver, um problema mais sério de pobreza, injustiça social e debilitação das estruturas do Estado. (...) Nossa cooperação com o Haiti não se deu sem alguma resistência interna. Afinal, o Brasil é também um país com enormes carências sociais. Com grandes dificuldades, inclusive na área de segurança. Mas essa é uma lição que aprendi com os próprios brasileiros de origem mais humilde. Não é preciso ser rico para ser solidário. Creio que a contribuição do Brasil foi importante para que, hoje, o Haiti tenha uma perspectiva de futuro. Nada mais natural, portanto, do que o Brasil acolher esta reunião, que buscará avaliar a cooperação internacional no Haiti nos últimos dois anos, e definir rumos a serem seguidos, a partir das prioridades definidas pelo novo governo haitiano. Esta reunião também deverá preparar a Conferência de Doadores, a ser realizada em julho, em Porto Príncipe. É fundamental manter essa dinâmica e demonstrar que a comunidade internacional continuará ao lado do Haiti. A presença da Minustah no Haiti continuará sendo necessária. O próprio Presidente Préval afirmou desejar que as tropas da ONU permaneçam no País. Mas o Presidente Préval também deixou claro que os termos do mandato da Minustah devem ser reformulados, tendo em mente a nova situação. Nas palavras do presidente, "bulldozers e betoneiras devem ocupar o lugar dos carros de

R. Inter. Interdisc. INTERthesis, Florianópolis, v.5, p. 47-65, jan./jul. 2008. 
combate". O Haiti precisa de um novo paradigma de cooperação internacional, com ênfase em projetos que produzam resultados focalizados no combate à pobreza e fortaleçam a capacidade do Estado de prestar serviços à população. Ao mesmo tempo, a comunidade financeira internacional deve compreender a especificidade da situação haitiana, e adaptar certos requisitos burocráticos, talvez em si mesmo válidos, mas que no passado freqüentemente sacrificaram as possibilidades de uma real cooperação com este que é o único país de menor desenvolvimento relativo do nosso continente.

Como visto, a atuação brasileira no Haiti inaugura uma nova forma de pensar as relações internacionais, mormente focada na construção de um "novo paradigma de cooperação internacional, com ênfase em projetos que produzam resultados focalizados no combate à pobreza e fortaleçam a capacidade do Estado de prestar serviços à população" (AMORIM, 2006). Tal paradigma, trouxe elementos fundamentais para se falar em uma nova concepção de solidariedade internacional, baseada na transnacionalização de políticas públicas, com vistas a fomentar o fortalecimento do Estado, considerando que para um país se constituir democrático e justo precisa da realização eficaz de políticas sociais (ZALUAR, 1997).

$\mathrm{Na}$ realidade, pode-se dizer que o Brasil inaugura uma nova espécie de solidariedade internacional, marcada por uma interlatinamericanidade (cooperação entre países do hemisfério sul), onde se passa a conceber a ajuda humanitária internacional não mais apenas como um simples envio de tropas ou mantimentos, mas sim como a própria formulação de políticas públicas transnacionais, com o objetivo claro de criar bases sólidas para a reconstrução de nações menos favorecidas ou assoladas por conflagrações belicosas e instabilidades políticas.

Por seu turno, este novo paradigma de solidariedade internacional, parte do princípio de que as sociedades oneradas por condições desfavoráveis, como é o caso do Haiti, e aqui valho-me da teoria defendida por John Rawls (2001) em "O direito dos povos" (publicada originalmente em inglês com o título The Law of Peoples), embora não sejam expansionistas nem agressivas, necessitam da formação de uma sólida base política, social, tradição cultural, bem como de recursos materiais e tecnológicos necessários para que se tornem sociedades bem ordenadas.

Os elementos fundamentais que caracterizam este novo paradigma jurídico são, sem dúvida alguma, o nítido dever de assistência e de afinidade, entendido como a busca de elevar os pobres do mundo até que se tornem cidadãos livres e iguais de uma 
sociedade razoavelmente liberal ou membros de uma sociedade hierárquica decente (RAWLS, 2001); e a construção de um novo conceito de diplomacia solidária que pode ser compreendida como a aplicação de uma ação coletiva internacional feita por países intervenientes num conflito interno ou internacional, sem que haja interesses de ordem material ou estratégica, e movidos por dever de consciência (VALLER FILHO, 2007).

Na realidade, o cerne da questão diz respeito à formulação de um novo conceito de solidariedade que transcende os meros limites territoriais de um Estado, cujo interesse precípuo será fomentar a reconstrução de nações afligidas, mesmo que não sejam próximas geograficamente ou historicamente.

Neste diapasão, pode-se dizer que, no caso haitiano, a política externa brasileira reconheceu razões de ordem moral, espontânea, incoercível para uma intervenção que foi definida pelo Ministro das Relações Exteriores como expressão do profundo comprometimento do País em termos políticos e emocionais (VALLER FILHO, 2007).

\section{CONSIDERAÇÕES FINAIS}

Como visto, a sociedade, de uma forma geral, tem vivido um momento ímpar em sua história. Assistimos o mundo passar por diversas transformações importantíssimas no âmbito de suas relações sociais, políticas e econômicas. Em face dessas mudanças nos deparamos com o crescente número de conflitos armados, instabilidades políticas e graves crises institucionais que surgem no interior de vários países e que nos fazem questionar a maneira pela qual os diversos povos do mundo têm proporcionado aos seus vizinhos onerados o mínimo de apoio necessário à reconstrução de sua identidade nacional.

Em face dessa atual realidade, surge um novo conceito de solidarismo internacional, baseado principalmente nas idéias vinculadas ao dever de assistência e de afinidade, e a construção de um modelo de diplomacia solidária, materializadas em uma sensível e eficaz transnacionalização de políticas públicas, cujo objetivo de maior destaque será fomentar o crescimento social e econômico de nações menos favorecidas ou que tenham sido alvos constantes de crises e instabilidades políticas, como é o caso da intervenção brasileira no Haiti.

Entrementes, não que dizer que se estar a propor um conceito restrito apenas às

R. Inter. Interdisc. INTERthesis, Florianópolis, v.5, p. 47-65, jan./jul. 2008. 
situações vividas na América do Sul, mas sim empreender o desenvolvimento de um novo paradigma jurídico de transnacionalização de políticas públicas capaz de promover a adoção de novas práticas de intervenção humanitária que transcenda os limites geográficos mais próximos, proporcionando a geração de efeitos duradouros na reconstrução de regiões mais distantes como, por exemplo, em países da África e Ásia, tenhamos ou não com eles afinidades sócio-culturais.

Para tanto, propôs-se uma abordagem transdisciplinar capaz de fornecer o quadro teórico mais convincente para integrar, neste novo universo paradigmático, os dados conceituais hodiernos, oferecendo, ao mesmo tempo, um novo quadro de referências apropriado para escorar os nossos questionamentos acerca do solidarismo internacional.

Conclui-se, portanto, que o Brasil inaugura uma nova espécie de solidariedade internacional, marcada por uma interlatinamericanidade, na qual se passa a conceber a ajuda humanitária internacional não mais apenas como um simples envio de tropas ou mantimentos, mas sim como a própria formulação de políticas públicas transnacionais, com o objetivo claro de criar bases sólidas para a reconstrução de nações menos favorecidas ou assoladas por conflagrações belicosas e instabilidades políticas.

\section{REFERÊNCIAS}

AGUILLAR, Sérgio Luis Cruz. As forças de paz do Brasil: balanço. In: BRIGAGÃO, Clóvis (Org.); PROENÇA JÚNIOR, Domício. Brasil e o mundo: novas visões. Rio de Janeiro: Francisco Alves, 2002. p. 363-439.

ALMEIDA, João Carlos. Antropologia da Solidariedade. Disponível em: <http://www.hottopos.com/notand14/joao.pdf>. Acesso em: 13 nov. 2007.

ALMINO, João. Inserção internacional de segurança do Brasil: a perspectiva diplomática. In: BRIGAGÃO, Clóvis (Org.); PROENÇA JÚNIOR, Domício. Brasil e o mundo: novas visões. Rio de Janeiro: Francisco Alves, 2002. p. 27-86.

AMORIM, Celso Luiz Nunes. Discurso na Reunião Especial do Conselho de Segurança das Nações Unidas sobre o Haiti. Disponível em:

<http://www.mre.gov.br/portugues/politica_externa/discursos/discurso_detalhe3.asp?ID_DISCURS $\mathrm{O}=2548>$. Acesso em: 31 out. 2007.

Haiti. Disponível em:

Discurso na sessão de abertura da Reunião Internacional de Alto Nível sobre o

<http://www.mre.gov.br/portugues/politica_externa/discursos/discurso_detalhe3.asp?ID_DISCURS $\mathrm{O}=2843>$ Acesso em: 19 set. 2007.

R. Inter. Interdisc. INTERthesis, Florianópolis, v.5, p. 47-65, jan./jul. 2008. 
BALERA, Wagner. Justiça social: direitos de solidariedade configuram cidadania mundial. Disponível em: http://conjur.estadao.com.br//static/text/38647,1. Acesso em: 14 nov. 2007.

CARDOSO, Afonso José Sena. O Brasil nas operações de paz das Nações Unidas. - Brasília: Instituto Rio Branco; Fundação Alexandre de Gusmão; Centro de Estudos Estratégicos, 1998. 169 p.

CARTA DA TRANSDICIPLINARIEDADE. In: Educação e transdisciplinaridade // / coordenação executiva do CETRANS. - São Paulo : TRIOM, 2002. Disponível em:

http://www.unesco.org.br/publicacoes/livros/educatransdll/mostra_documento. p. 193-197

DUVIGNAUD, Jean. A solidariedade: laços de sangue, laços de razão. Lisboa: Instituto Piaget, 1995. $213 \mathrm{p}$.

FARIAS, José Fernando de Castro. A origem do direito de solidariedade. - Rio de Janeiro:

Renovar, 1998. 304 p.

GRONDIN, Marcelo. Haiti: Cultura, poder e desenvolvimento. 1. ed. - São Paulo: Brasiliense, 1985. $101 \mathrm{p}$.

História do Haiti. Disponível em: <http://pt.wikipedia.org/wiki/Hist\%C3\%B3ria_do_Haiti>. Acesso em 30 out. 2007.

LOLIS, Dione. Solidariedade e política social. Disponível em:

<http://www.ssrevista.uel.br/c_v3n2_solidariedade.htm>. Acesso em: 13/11/2007

PEREIRA, Augusto Heleno Ribeiro. Operação de paz no Haiti. - Brasília: Gabinete de Segurança Institucional; Secretaria de Acompanhamento e Estudos Institucionais, 2005. 38 p.

RAWLS, John. O direito dos povos. Trad. Luís Carlos Borges; revisão técnica Sérgio Sérvulo da Cunha. - São Paulo: Martins Fontes, 2001. 259 p.

CONSELHO DE SEGURANÇA DA ORGANIZAÇÃO DAS NAÇÕES UNIDAS. Resolução $n^{\circ} 1542$, aprovada pelo Conselho de Segurança em sua $4961^{\text {a }}$ sessão, celebrada em 30 de abril de 2004. Disponível em: <http://www.un.org/spanish/docs/sc04/scrl04.htm>. Acesso em: 01 nov. 2007.

RODRIGUES, José Albertino (org). Émile Durkheim: sociologia. 9. ed. São Paulo: Ática, 2005. 208 p.

RODRIGUES, Simone Martins. Segurança internacional e direitos humanos: a prática da intervenção humanitária no pós-guerra fria. - Rio de Janeiro: Renovar, 2000. 277 p.

SEITENFUS, Ricardo. De Suez ao Haiti: a participação brasileira nas Operações de Paz. Disponível em: <http://www.seitenfus.com.br/arquivos/Seitenfus_-_De_Suez_ao_Haiti.pdf>. Acesso em: 01 nov. 2007.

R. Inter. Interdisc. INTERthesis, Florianópolis, v.5, p. 47-65, jan./jul. 2008. 
SEITENFUS, Ricardo. Haiti, a soberania do ditadores. Porto Alegre: Sólivros, 1994. Disponível em: <http://www.brasilhaiti.com/arquivos/HaitiUma_histria_sui_generis_1_.pdf>. Acesso em: 30 out. 2007.

TÉVOÉDJRÉ, Albert. A pobreza, riqueza dos povos: a transformação pela solidariedade. Trad. Reinaldo Matias Fleuri. - São Paulo: Cidade Nova; Rio de Janeiro: Vozes. 1981. 205 p.

VALLER FILHO, Wladimir. O Brasil e a crise haitiana: a cooperação técnica como instrumento de solidariedade e de ação diplomática. - Brasília: FUNAG, 2007. 396 p.

VENTURA, Deisy. Monografia jurídica: uma visão prática. - Porto Alegre: Livraria do Advogado, 2000. 152 p.

ZALUAR, Alba. Exclusão e políticas públicas: dilemas teóricos e alternativas políticas. Revista Brasileira de Ciências Sociais, São Paulo, v. 12, n. 35, 1997. Disponível em:

$<$ http://www.scielo.br/scielo.php?script=sci_arttext\&pid=S0102-69091997000300003\&lng= en\&nrm=iso>. Acesso em 18 set. 2007.

Artigo entregue em 20 de fevereiro de 2008. Artigo aceito em 19 de Junho de 2008.

R. Inter. Interdisc. INTERthesis, Florianópolis, v.5, p. 47-65, jan./jul. 2008. 